\title{
Primary and "Transfer" Seizure Development in the Kindled Rat
}

\author{
W. MCINTYRE BURNHAM
}

SUMMARY: An investigation was made of both primary and "transfer" kindling as they occur in ipsilateral limbic sites. Primary kindling was found to involve progressive growth of afterdischarge $(A D)$, propagation and convalsive behavior. It was noted that $A D$ growth did not take place gradually but occurred in sudden, large increments. "Transfer" (a significant acceleration of secondary kindling) was found at every secondary limbic site. It was associated with the early appearance of full-blown AD's, super-normal propagation, and well-developed seizures. The post-transfer interference of primary site function previously reported by Goddard et al was also found, but it occurred in significant amounts only after transfer kindling of the amygdala. It is believed that the data offer some support for both of the hypothetical mechanisms of transfer which have been proposed.

RÉSUMÉ: Cet article rapporte une étude du "kindling" primaire ou de transferi aux sites limbiques ipsilatéraux et conclut qu'il existe au moins deux mécanismes possibles ou transfert (accélération significative du "kindling", secondaire).

From the Psychology Department, McGill University.

Reprint requests to Dr. W. M. Burnham, Limbic Mechanisms Laboratory, Department of Pharmacology, Room 4309, Medical Sciences Building, University of Toronto, Toronto, Ontario, M5S 1A8, Canada.

\section{INTRODUCTION}

It seems probable that the neural reorganization which occurs during kindling extends far beyond the actual site of electrical stimulation. Several lines of evidence point to this conclusion, perhaps the most compelling being the finding that after major seizures have been kindled from one site, other sites within the same brain also show a greatly enhanced potential for triggering them (Goddard et al, 1969; Racine, 1972b). This enhanced potential, termed the "transfer effect", is seen in limbic-kindled animals as an acceleration in the rate of onset of generalized convulsions ("GC's"), while in anterior neocortical-kindled animals, where convulsions always accompany afterdischarge ("AD"), it takes the form of unexpectedly strong initial motor seizures and an early development of tonic extensions. That transfer involves reorganization outside the kindled focus is indicated by the fact that it occurs full strength even when the original ("primary") focus has been destroyed by a lesion (Racine, 1972b). It apparently does not, however, involve an indiscriminate spread of epileptic hyper-excitability since AD thresholds outside the primary focus are found to be normal or even slightly elevated (Racine, 1972a).

Previous studies (Racine, 1972b; Goddard et al, 1969) have demonstrated transfer between a number of contralateral structures, both homologous (the amygdalas, the hippocampi and the anterior cortices) and non-homologous (the spetal area after contralateral amygdaloid kindling; cortical area 40 after contralateral area 6 kindling). It has also been demonstrated between one pair of ipsilateral structures, the amygdala and the septal area (Goddard et al, 1969). The present study was designed as a further investigation of transfer in ipsilateral limbic sites. A number of new combinations of sites were tried, and a careful analysis of seizure development, both primary and transfer, was undertaken. An attempt was also made to demonstrate the inhibition of the primary kindling focus ("posttransfer interference") which has been reported to follow transfer kindling (Goddard et al, 1969; Mclntyre and Goddard, 1973).

\section{MATERIALS AND METHODS General:}

A principal aim of the present study was to compare primary and transfer kindling in the same structures. Chronic stimulating-recording electrodes were therefore implanted in pairs, one in each of two different ipsilateral limbic sites. During the first phase of the experiment, half of the animals with any given electrode pairing received kindling stimulation in one of the sites and half in the other (the "primary" sites). During the second phase of the experiment, stimulation was switched over to the previously unstimulated sites (the "transfer" sites) in each animal. In this way, both primary and transfer data were obtained for each structure. In the final phase of the experiment, stimulation was switched back to the primary sites in order to look for post-transfer interference.

\section{Surgery:}

Eighty male, black-hooded rats of the Royal Victoria Hospital strain (240-280 grams at surgery) served as subjects ("S's"). Each S was implanted with two bipolar stainless steel electrodes using techniques 
and procedures previously described by Racine (1972a). Four different ipsilateral limbic sites were used for implantation during the whole course of surgery: the basolateral amygdala; the lateral septal area; the dorsal hippocampus; and the ventral hippocampus. Each site was paired with each other site in an equal number of S's except for the dorsal and ventral hippocampus which were not paired with each other.

\section{Primary Kindling:}

Following a 2 week post-surgical period for recovery and handling, primary sites were randomly assigned. AD thresholds were determined by the half-split method (Racine, 1972a), and primary kindling stimulation was begun. Kindling was done according to the "suprathreshold" procedure originated by Racine (1972b). Stimulation consisted of a 1 second train of $1 \mathrm{msec}$. $60 \mathrm{~Hz}$ biphasic square wave pulses given once per day at an intensity which was $130 \%$ of the subject's original AD threshold (usually below $500 \mu$ a peak to peak).

Primary site stimulation was continued until convulsive behavior had appeared and 10 GC's had been recorded. During the occurrence of GC's in this and later phases of the study, S's were stimulated not daily but every second day to avoid the threshold rises reported to accompany daily convulsions (Racine, 1972b).

\section{Transfer Kindling:}

After $10 \mathrm{GC}$ 's had been triggered from the primary site, stimulation was begun at the transfer site and the kindling procedure was repeated. Threshold testing was omitted at secondary sites so that immediate transfer, if any, could be observed. Stimulation intensity was set at double the average threshold found for primary S's at that site.

\section{Retesting of the Primary Site:}

After five GC's had been triggered from the transfer site, stimulation of the primary site was re-initiated using the same stimulation parameters which had been employed for primary kindling.
Data Collection and Scoring:

EEG recordings were taken at both primary and transfer sites during every phase of testing. The number of AD's required to elicit the first GC (the "kindling rate") was noted as well as the latency, duration and strength of any convulsive behavior which occurred. Strength of convulsion was rated according to Racine's "seizure stages" (Racine, 1972b). Racine's stages 3, 4, and 5 were scored as GC's.

\section{Histology:}

At the end of all testing, S's were perfused and frozen brain sections were taken, stained with thionin, and examined under the microscope. Histological reconstructions of the electrode placements are seen in Figure 1. The data from S's with inaccurate placements were discarded, which, along with casualties due to illness, reduced the total number to sixty-three.

\section{RESULTS}

Rates of Seizure Development a) During Primary Kindling: Goddard et al, (1969) have reported that when different forebrain sites are kindled, different numbers of stimulations are required to trigger the first GC. The amygdala, for instance, caused the quickest kindling in their experiments requiring an average of only 15 daily stimulations for GC onset. Other limbic sites had longer kindling rates, including the septal area (55 daily stimulations) and the hippocampus ( 77 daily stimulations).

Some question was later raised about these findings when Racine (1972b) discovered that stimulation which does not produce AD does not promote the development of GC's. Goddard et al had used a low level of standard stimulation and had not done electrographic recording, so it seemed possible that they might have included a number of sub-

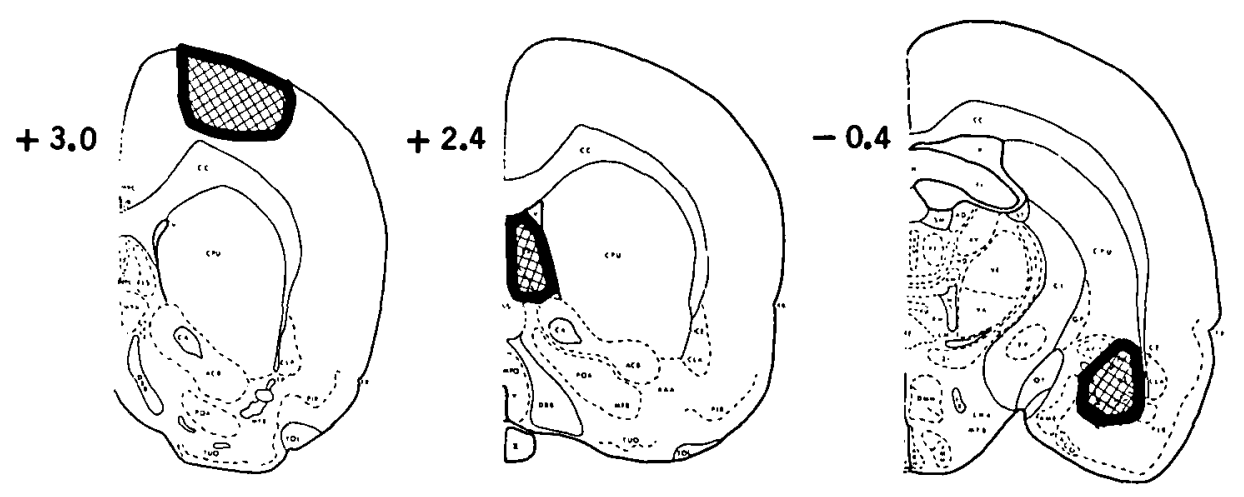

C OR T

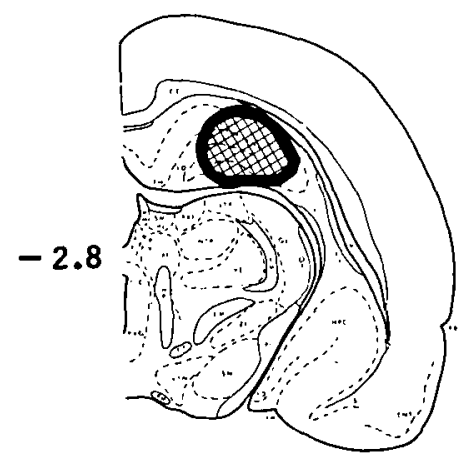

DH P C
S E P T

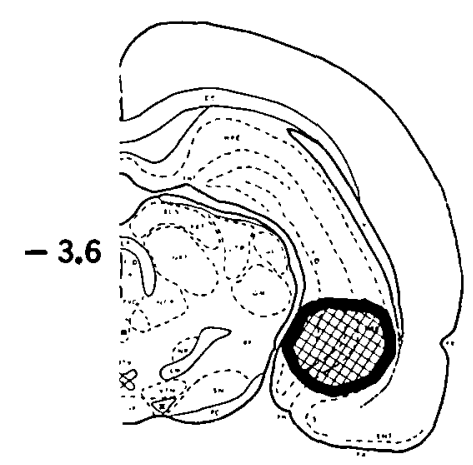

V HPC

Figure 1-Electrode placements as verified by histological examination. Crosshatched areas indicate the regions in which electrode tips were found. (Diagrams from Pellegrino and Cushman, 1967). A-P co-ordinates relative to bregma (millimeters) are indicated to the left of each section. 
threshold stimulations in their counts for high-threshold structures. Racine suggested that AD's should be counted rather than daily stimulations when kindling rates were determined. Column 1 of Table 1 indicates kindling rates, measured in AD's to first GC, for the primary sites studied in the present experiment. These data generally support Goddard et al 's original concept. Significantly different kindling rates were found in different sites, and the amygdala did yield the shortest average rate (10.6 AD's), the septal area an intermediate rate (17.4 AD's), and the dorsal hippocampus the longest rate ( $37.3 \mathrm{AD}$ 's). It is interesting to note that the data show a significant difference between the dorsal and ventral parts of the hippocampus, the ventral part having an intermediate rate similar to the septal area (20.6 AD's). Close scrutiny of the hippocampal data suggests the possibility of even further differences related to anatomical subdivision. Only a few absolutely clear-cut placements could be found, but these suggest that in both dorsal and ventral S's the hippocampus proper kindled nearly twice as fast as the fascia dentata. Further studies are in progress to test this possibility.

The fact that kindling rates in the present experiment were generally shorter than those previously reported may indicate that Goddard et al did include some subthreshold stimulations in their counts. These shorter rates, however, may also reflect strain differences which have recently been shown to affect the speed of kindling (Racine, Burnham, Gartner and Levitan, 1973).

b) During Transfer Kindling: The essence of transfer is an accelerated rate of seizure development during secondary kindling. Column 2 of Table 1 presents kindling rates for the transfer sites studied in the present experiment. Significances of the differences between these and the primary rates, calculated by the non-parametric Mann-Whitney U test due to the greatly reduced variance of the transfer data, are indicated in Column 3. As Column 3 indicates, significant amounts of trans- fer were seen in every secondary site tested. Transfer appears to be a general phenomenon, found throughout the limbic system and not limited to particular subsystems, structures, or pathways.

Certain differences did appear to exist in the amounts of transfer produced by the various combinations of sites. (Amount of transfer is expressed as per cent reduction in kindling rate in Column 4 of Table 1). The septal area, for instance, caused more transfer in the hippocampus than did the amygdala. The hippocampus likewise caused more septal transfer than the amygdala. These findings would seem to suggest the importance of direct connections in the development of the transfer. On the other hand, large amounts of transfer were seen in the amygdala after primary kindling of the septal area and the hippocampus. The amygdala does not have strong direct connections with either of these structures. Amounts of transfer will be discussed further in a later section of this paper.

The hippocampal S's once again exhibited a bimodal distribution which seemed related to anatomical subdivision. The scanty data allow only preliminary judgements, but generally speaking the fascia dentata placements seemed to show good transfer while the hippocampal proper placements showed very little.

\section{Development of Local Discharge}

a) During Primary Kindling: The AD's recorded at stimulation sites during primary kindling followed a

TABLE 1

Primary and Transfer Kindling Rates ( $A D^{\prime}$ 's to lst GC)

\begin{tabular}{|c|c|c|c|c|c|c|c|}
\hline Site & $\begin{array}{c}1^{*} \\
\text { - Primary } \\
\text { Kindling Rate }\end{array}$ & $\begin{array}{l}\overline{\mathrm{m}} \operatorname{Tr} \\
\text { Kindlir }\end{array}$ & isfer & $\begin{array}{l}3^{* *} \\
\text { P vs. } 1\end{array}$ & $\begin{array}{c}4 \\
\text { \% Savin } \\
2 \text { vs. } 1\end{array}$ & $\begin{array}{c}5 \\
\text { \% Immediate } \\
\text { Transfer GC }\end{array}$ & $\begin{array}{c}\quad 6 * * * \\
\text { m Previous } \\
\text { Reactive } A D \text { 's }\end{array}$ \\
\hline \multirow[t]{3}{*}{ AMYG } & \multirow[b]{2}{*}{$(6-19)$} & $\begin{array}{l}\text { After } \\
\text { SEPT }\end{array}$ & $\begin{array}{r}2.0 \\
(1-3) \\
\mathrm{N}=5 \\
\end{array}$ & $=0.0006$ & 81.1 & 40.0 & $\star 13.6$ \\
\hline & & $\begin{array}{l}\text { After } \\
\text { dHPC }\end{array}$ & $\begin{array}{l}1.8 \\
(1-3) \\
N=5 \\
\end{array}$ & $=0.0006$ & 83.0 & 40.0 & 9.2 \\
\hline & $\mathrm{N}=25$ & $\begin{array}{l}\text { After } \\
\text { vHPC }\end{array}$ & $\begin{array}{l}1.5 \\
(1-3) \\
\mathrm{N}=6 \\
\end{array}$ & $=0.0002$ & 85.8 & 66.7 & $\star 15.7$ \\
\hline \multirow[t]{3}{*}{ SEPT } & 17.4 & $\begin{array}{l}\text { Af ter } \\
\text { AMYG }\end{array}$ & $\begin{array}{l}8.2 \\
(5-13) \\
N=5\end{array}$ & $=0.009$ & 52.9 & 0.0 & 15.0 \\
\hline & $(7-29)$ & $\begin{array}{l}\text { After } \\
\text { dHPC }\end{array}$ & $\begin{array}{r}2.4 \\
(1-6) \\
\mathrm{N}=7 \\
\end{array}$ & $=0.0001$ & 86.2 & 57.1 & $\star \quad 47.6$ \\
\hline & $N=21$ & $\begin{array}{l}\text { After } \\
\text { vHPC }\end{array}$ & $\begin{array}{r}2.0 \\
(1-3) \\
\mathrm{N}=6 \\
\end{array}$ & $<0.0003$ & 88.5 & 33.3 & $\star \quad 29.3$ \\
\hline \multirow[t]{2}{*}{$\mathrm{dHPC}$} & 37.3 & $\begin{array}{l}\text { After } \\
\text { AMYG }\end{array}$ & $\begin{array}{l}24.0 \\
(4-50) \\
N=8 \\
\end{array}$ & $=0.05$ & 35.7 & 0.0 & 11.6 \\
\hline & $\begin{array}{l}(25-60) \\
N=14\end{array}$ & $\begin{array}{l}\text { After } \\
\text { SEPT }\end{array}$ & $\begin{array}{l}14.5 \\
(7-32) \\
\mathrm{N}=8\end{array}$ & $=0.002$ & 61.1 & 0.0 & 14.9 \\
\hline \multirow[t]{2}{*}{ vHPC } & \multirow[b]{2}{*}{$\begin{array}{l}(9-28) \\
N=13\end{array}$} & $\begin{array}{l}\text { After } \\
\text { AMYG }\end{array}$ & $\begin{array}{l}10.7 \\
(1-26) \\
\mathrm{N}=7\end{array}$ & $=0.02$ & 48.1 & 14.3 & 9.4 \\
\hline & & $\begin{array}{l}\text { After } \\
\text { SГPT }\end{array}$ & $\begin{array}{l}5.2 \\
(2-9) \\
N=6\end{array}$ & $<0.002$ & 74.8 & 0.0 & 1.7 .8 \\
\hline
\end{tabular}

* Analysis of variance for the data in Column 1 indicates overall significance. Individual comparisons (Scheffé Method; Winer, 1962) show that all groups differ significantly ( $5 \%$ level or better) except the septals and ventral hippocampals.

** One-tailed probabilities are calculated by the Mann-Whitney U Test.

*** "Stars" indicate groups in which the mean number of reactive AD's in transfer sites during primary kindling was greater than or approximately equal to the mean primary kindling rate.

(Complete details of the statistical analyses presented in tables may be found in Burnham, 1971). 
pattern of growth and development already described by previous investigators (Goddard et al, 1969; Racine, 1972b). With daily repetition, the brief "early" AD's seen at first grew longer, greater in amplitude, and more complex in wave form (Figure 2).

The records of ten subjects in each primary group were chosen at random for detailed analysis, AD duration being picked as the most easily measured index of growth. Average $A D$ durations for these subjects at various different kindling "landmarks" are presented in Table 2. These data show significant growth in every group, durations increasing from the first $A D$ to the first GC where they give a sudden jump and then plateau at a "mature" level which is 3 to 4 times their early duration. It is interesting to note that despite the varying structures involved, average $A D$ durations for the different groups were quite similar at all the "landmark" points throughout kindling. (Fast kindling groups naturally reached the landmarks sooner.) The only group showing even a trend toward difference was the dorsal hippocampal group where the "silent period", a local inhibitory phenomenon previously described by Racine (1972b), appeared to limit growth. The similarity of $\mathrm{AD}$ durations at landmark points suggests the possibility of some basic mechanism common to seizure growth regardless of stimulation site.

The dramatic $A D$ growth seen at the onset of GC's has previously been noted by Racine (1972b), who described it as occurring a "few days" before the occurrence of his "maximal" (Stage 5) seizures. Due to the different seizure criterion employed in the present experiments, we can now locate it more specifically as occurring with the first GC. Racine states that this increase failed to occur in some of his S's. A few of our S's also failed to show it. Careful examination of individual records revealed that most of these failures occurred in S's where medium or long AD's had already developed bebefore GC onset. S's often do develop mature AD's before the first GC,
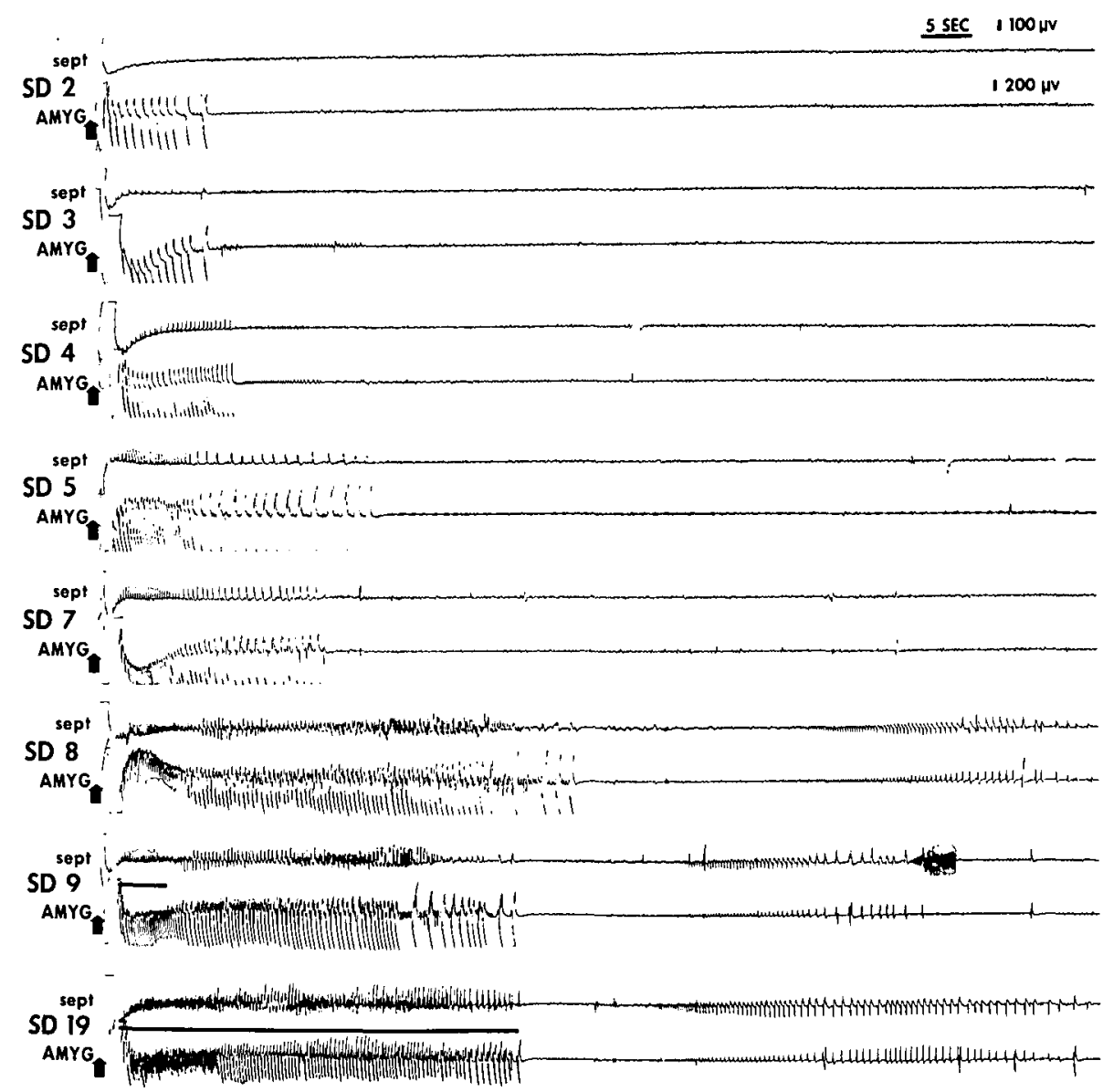

Figure 2-AD's recorded during primary kindling of the amygdala. The lower trace of each pair represents the local AD. The upper trace illustrates propagation to the septal area. Vertical arrows indicate the point of stimulation. Heavy horizontal lines indicate GC activity. and these subjects may not show AD growth when GC onset occurs. If, however, mature AD's have not developed by GC onset, they will tend to do so at that time.
Individual growth profiles plotted for single S's revealed a further interesting aspect of AD growth. At least in the amygdaloid and septal S's, much of the growth tended to
TABLE 2

Local AD Durations (Sec) at "Landmark" Points During Primary Kindling*

\begin{tabular}{|c|c|c|c|c|c|c|}
\hline \multicolumn{2}{|l|}{ Site } & First $\mathrm{AD}$ & $\begin{array}{l}\text { Last } A D \\
\text { Before } G C^{\prime} s\end{array}$ & $\begin{array}{c}\text { First } \mathrm{AD} \\
\text { During } G C^{\prime} s\end{array}$ & $\begin{array}{c}\text { Tenth } \mathrm{AD} \\
\text { During } \mathrm{GC} \text { 's }\end{array}$ & $\overline{\mathrm{m}}_{\mathrm{R}}$ \\
\hline $\begin{array}{l}\text { AMYG } \\
N=10\end{array}$ & $\begin{array}{l}\overline{\mathbf{m}} \\
\mathrm{r}\end{array}$ & $\begin{array}{c}20.1 \\
(5.5-45.0)\end{array}$ & $\begin{array}{c}41.5 \\
(22.5-70.0)\end{array}$ & $\begin{array}{c}75.5 \\
(32.5-145.0)\end{array}$ & $\begin{array}{c}70.0 \\
(49.0-95.0)\end{array}$ & 51.8 \\
\hline $\begin{array}{l}\text { SEPT } \\
N=10\end{array}$ & $\begin{array}{l}\overline{\mathrm{m}} \\
\mathrm{r}\end{array}$ & $\begin{array}{c}17.3 \\
(3.5-35.0)\end{array}$ & $\begin{array}{c}47.1 \\
(8.0-95.0)\end{array}$ & $\begin{array}{c}76.3 \\
(28.5-111.0)\end{array}$ & $\begin{array}{c}76.0 \\
(44.5-109.0)\end{array}$ & 54.2 \\
\hline $\begin{array}{l}\mathrm{d} \mathrm{HPC} \\
\mathrm{N}=10\end{array}$ & $\begin{array}{c}\overline{\mathrm{m}} \\
\mathrm{r}\end{array}$ & $\begin{array}{c}21.1 \\
(15.0-35.0)\end{array}$ & $\begin{array}{c}35.1 \\
(21.0-53.0)\end{array}$ & $\begin{array}{c}46.1 \\
(26.0-62.5)\end{array}$ & $\begin{array}{c}56.1 \\
(23.5-73.0)\end{array}$ & 39.6 \\
\hline $\begin{array}{l}\mathrm{VHPC} \\
\mathrm{N}=10\end{array}$ & $\begin{array}{l}\overline{\mathrm{m}} \\
\mathrm{r}\end{array}$ & $\begin{array}{c}18.8 \\
(4.0-43.0)\end{array}$ & $\begin{array}{c}34.0 \\
(11.5-49.0)\end{array}$ & $\begin{array}{c}83.3 \\
(26.0-178.5)\end{array}$ & $\begin{array}{c}91.4 \\
(41.5-139.0)\end{array}$ & 56.9 \\
\hline & $\overline{\mathrm{m}}_{\mathrm{C}}$ & 19.4 & 39.4 & 70.3 & 73.4 & \\
\hline
\end{tabular}

* Analysis of variance indicates overall significance, and a columns effect significant at the $1 \%$ level. Individual comparisons (Scheffé Method) for the column means: 1st vs. 2nd, $p<0.005 ; 2$ nd vs. 3rd, $p<0.005 ; 3$ rd vs. 4th, ns. 
occur in sudden, large increments. Profiles plotted for these S's resemble a series of steps or plateaus (Figure 3 A \& B). Most profiles consisted of 3 or 4 such plateaus, one often occurring about the time of seizure onset. Comparing S's profiles with each other, there seemed to be some rough similarity in at least the early plateaus displayed: There was sometimes a plateau around 10 seconds; often a plateau around 20 seconds; usually a plateau around 40 seconds and so forth.

Examination of EEG records at the points where sudden increments occurred showed that the added segments of discharge often had their own patterns, distinguishable from the original segments on the basis of amplitude, frequency or polarity (Figure 2, SD 4 \& 5). Mature AD's often consisted of several such distinguishable patterns. The appearance of a new AD segment was sometimes foreshadowed by a day or two of very low amplitude "blunt" spiking in the locus it was about to occupy. These low amplitude spikes had the appearance of projected discharge (See Figure 2, AMYG traces on SD $3 \& 4$ ).

A somewhat different pattern was seen in the records of hippocampal $\mathrm{S}$ 's (Figure 3C). Here the "silent period" severely curtailed local AD growth which soon lagged behind that of propagated AD's. Only a very gradual increase occurred (as spiking invaded the "silent period") at least until GC onset. At that time even hippocampal S's often managed to generate a "step". A few ventral hippocampal S's which failed to display a "silent period" had incremental growth profiles like those of the amygdaloid and septal S's.

b) During Transfer Kindling: Two different explanations have been proposed for the transfer phenomenon: 1) that transfer sites, activated by propagated discharge during primary kindling, go through independent seizure development just as if they were being directly stimulated (Racine, 1972b); 2) that transfer sites simply "tie into" seizure circuits previously established by primary site activity (Goddard et al., 1969).

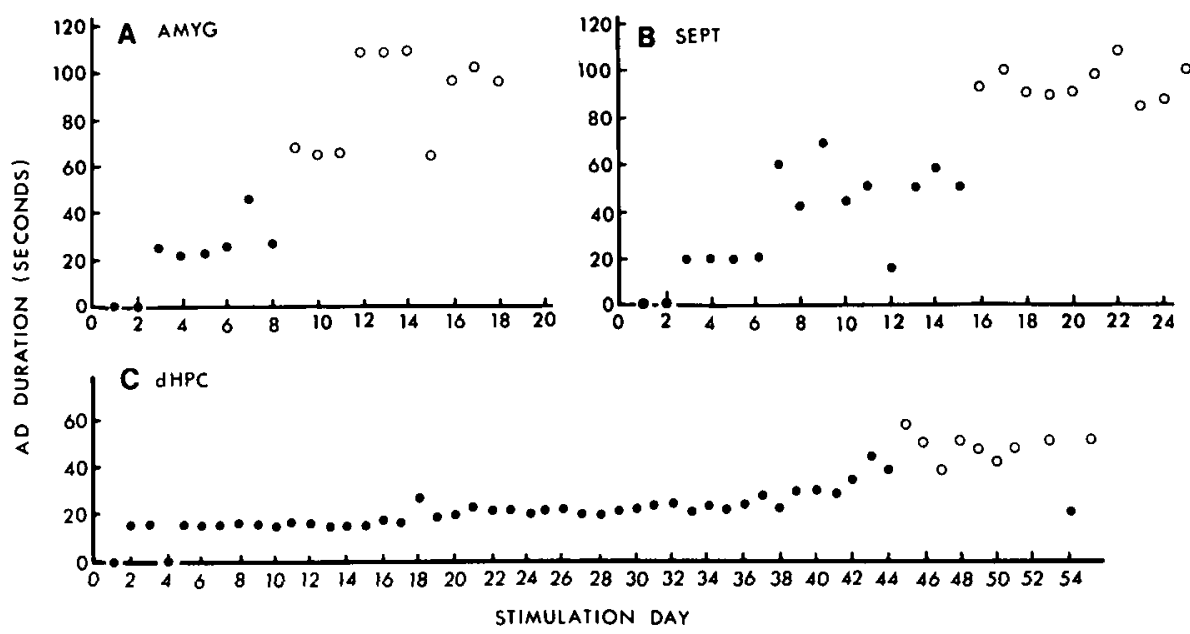

Figure 3-Profiles plotted for the growth of AD duration during primary kindling. Solid circles indicate AD's which triggered GC's. Open circles indicate AD's which did not trigger GC's. A and B: the incremental growth usually seen in amygdaloid and septal S's. C: the gradual growth pattern usually seen in hippocampal S's.
These different explanations would lead to different expectations about transfer site discharge. If transfer sites undergo independent development during primary kindling, they ought to show fairly mature AD's right from the start of transfer stimulation. If, on the other hand, they have been inactive, we should expect them to produce "early"
AD's which might suddenly lengthen as tying-in occurred.

$A D$ data from the present experiment seem to support the first hypothesis. Transfer site AD's tended toward maturity from the very start. They averaged significantly longer than initial primary AD's from the same structures (Table 3), and often showed mature
TABLE 3

Onset Durations (Sec) of Local $\mathrm{AD}^{\prime} \mathrm{s}$ in Primary and Transfer S's

\begin{tabular}{|c|c|c|c|c|}
\hline & ite & Primary & Transfer & $\overline{\mathbf{m}}_{\mathrm{R}}$ \\
\hline AMYG & $\begin{array}{l}\overrightarrow{\mathrm{m}} \\
\mathrm{r}\end{array}$ & $\begin{array}{c}20.1 \\
(5.5-45.0) \\
N=10\end{array}$ & $\begin{array}{c}54.7 \\
(8.0-87.0) \\
N=16\end{array}$ & 37.4 \\
\hline SEPT & $\begin{array}{l}\bar{m} \\
\mathrm{r}\end{array}$ & $\begin{array}{c}17.4 \\
(3.5-35.0) \\
N=10\end{array}$ & $\begin{array}{c}55.3 \\
(7.5-96.0) \\
N=18\end{array}$ & 36.3 \\
\hline $\mathrm{dHPC}$ & $\begin{array}{l}\overline{\mathrm{m}} \\
\mathrm{r}\end{array}$ & $\begin{array}{c}21.2 \\
(15.0-35.0) \\
N=10\end{array}$ & $\begin{array}{c}23.5 \\
(14.0-40.0) \\
N=16\end{array}$ & 22.3 \\
\hline vHPC & $\begin{array}{l}\bar{m} \\
\mathbf{r}\end{array}$ & $\begin{array}{c}18.7 \\
(4.0-43.0) \\
N=10\end{array}$ & $\begin{array}{c}35.8 \\
(11.0-71.0) \\
N=12\end{array}$ & 27.2 \\
\hline$\overline{\mathrm{m}}_{\mathrm{C}}$ & & 19.3 & 42.3 & \\
\hline
\end{tabular}

* Analysis of variance (unweighted means solution) for these data indicates overall significance, plus a significant columns effect ( $1 \% 1$ level) and a significant interaction ( $5 \%$ leve1). Subsequent individual comparisons show significant differences $(0.5 \%$ leve1) between the scores of the dorsal hippocampal transfer group and the amygdaloid and septal transfer groups. 
amplitudes and spike patterns from onset. This advanced maturity was most pronounced in the amygdaloid and septal S's which also showed the most transfer. Slower transfer subjects, including many of the hippocampals, showed AD growth profiles which resembled the latter parts of profiles plotted for primary subjects (Figure 4). Initial AD durations in dorsal hippocampal group were shorter than those in the other groups, and were actually not much different from initial primary durations (Table 3). This seems consistent, however, with the very gradual AD growth seen in dorsal hippocampals, until GC onset is near. Despite the fact that these slowkindling S's displayed a significant transfer effect, few of them were close to GC onset at the start of transfer stimulation.

\section{Development of Propagated Discharge}

a) During Primary Kindling: At the outset of primary kindling, the trans-
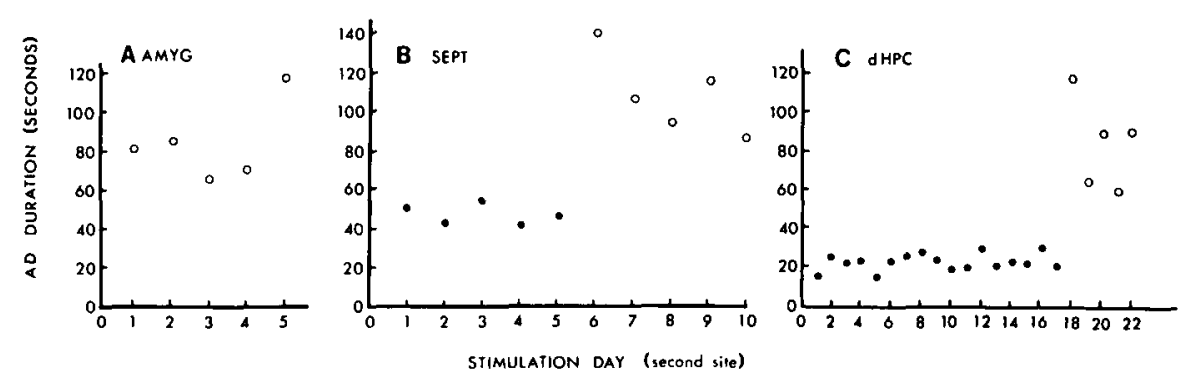

Figure 4-Profiles plotted for the growth of AD duration during transfer kindling. Solid circles indicate AD's which triggered GC's. Open circles indicate AD's which did not trigger GC's. A: S shows immediate transfer. B \& C: $S^{\prime}$ 's do not show immediate transfer. fer sites differed considerably in the degree of propagation they showed. In some secondary sites no driving at all was seen, in others small "blunt" spikes occurred, and sometimes even large, site-typical spikes were found. As Table 4 indicates, immediate propagation of some sort was quite widespread among these limbic structures, being found to a certain extent in every group. The amygdala was a particularly good "receiver", being driven $100 \%$ of the time by every other site, al-
TABLE 4

Percentage of S's Showing Propagation During The

First Primary (P) and Transfer (T) $\mathrm{AD}^{\prime} \mathrm{s}$

Recording Site

\begin{tabular}{|c|c|c|c|c|c|}
\hline & & AMYG & SEPT & $\mathrm{dHPC}$ & vHPC \\
\hline \multirow[t]{2}{*}{ AMYG } & $P$ & & $\begin{array}{r}20.0 \\
\mathrm{~N}=5\end{array}$ & $\begin{array}{r}12.5 \\
N=8\end{array}$ & $\begin{array}{r}28.6 \\
\mathrm{~N}=7\end{array}$ \\
\hline & $\mathrm{T}$ & & $\begin{array}{l}100.0 \\
N=5\end{array}$ & $\begin{array}{c}50.0 \\
\mathrm{~N}=4 *\end{array}$ & $\begin{array}{l}100.0 \\
\mathrm{~N}=6\end{array}$ \\
\hline \multirow[t]{2}{*}{ SEPT } & $P$ & $\begin{array}{l}100.0 \\
N=5\end{array}$ & & $\begin{array}{r}37.5 \\
N=8\end{array}$ & $\begin{array}{l}100.0 \\
\mathrm{~N}=6\end{array}$ \\
\hline & $\mathrm{T}$ & $\begin{array}{l}100.0 \\
N=5\end{array}$ & & $\begin{array}{r}85.7 \\
\mathrm{~N}=7\end{array}$ & $\begin{array}{l}100.0 \\
\mathrm{~N}=6\end{array}$ \\
\hline \multirow[t]{2}{*}{ dHPC } & $\mathrm{P}$ & $\begin{array}{l}100.0 \\
N=5\end{array}$ & $\begin{array}{r}71.4 \\
\mathrm{~N}=7\end{array}$ & & \\
\hline & $\mathrm{T}$ & $\begin{array}{l}100.0 \\
N=8\end{array}$ & $\begin{array}{l}100.0 \\
\mathrm{~N}=8\end{array}$ & & \\
\hline \multirow[t]{2}{*}{ vHPC } & $P$ & $\begin{array}{l}100.0 \\
\mathrm{~N}=6\end{array}$ & $\begin{array}{l}100.0 \\
N=6\end{array}$ & & \\
\hline & $T$ & $\begin{array}{l}100.0 \\
N=7\end{array}$ & $\begin{array}{l}100.0 \\
N=6\end{array}$ & & \\
\hline
\end{tabular}

* Data lost for one subject. though it propagated back to them much less strongly. The septal area and hippocampus were good at driving each other, as would be expected from their mutual interconnections. As Elul (1964) has suggested, the ventral hippocampus seemed more closely tied to other limbic structures than the dorsal hippocampus.

A number of previous experimenters have described the gradual growth of propagated AD which occurs during kindling of the amygdala or pyriform cortex (Racine, 1972b; Tanaka, 1972; Morrell, 1973; McIntyre and Goddard, 1973). In the present experiment, a similar pattern was seen throughout the limbic sites studied. As kindling progressed, non-responding sites tended to develop projected spiking, and projected spikes grew gradually or suddenly into large "sharp" site-typical spikes (Figure 2, Upper Traces). Propagation was almost universal in transfer sites by GC onset (one dorsal hippocampal failed to show it), and was universal by the end of primary stimulation.

Electroencephalographers recognize a difference between the passive response of a structure driven by a discharging neighbor ("projected discharge") and the active response seen when it begins its own independent self-sustained epileptic activity ("reactive discharge"). This distinction, though difficult to make on the basis of EEG recordings, is worth attempting since it seems likely that the spread of epileptic activity in the brain involves the progressive recruitment of structures into the "reactive discharge" state (Gastaut and Fischer-Williams, 1959; Racine, Burnham and Gartner, 
1973). In the present experiment, propagated discharge was scored as "reactive" whenever sharp sitetypical spikes were seen which approximated in size the discharge caused by direct electrical stimulation of the site. Due to the experimental design, the response of every site to direct stimulation was available for comparison.

At first, reactive propagation was seen only between the septal area and the hippocampus (it occurred in both directions), and from the ventral hippocampus to the amygdala. With repetition it began to develop in every secondary site. Table 5 indicates the average number of primary AD's necessary for this development to occur. It is interesting to note relative to this data that the site combinations which generated the most or least initial propagation were not always the ones which were quickest or slowest to produce reactive discharge. The amygdala, for instance, though a poor initial propagator, generated reactive discharge fairly quickly. By GC onset (Table 6), reactive propagation was widespread, being seen to a certain extent in every secondary site. By the completion of primary site stimulation it was almost universal, failures being seen only in two hippocampal subjects.

Before leaving the topic of primary propagation, it will be worthwhile to consider two hypotheses relating it to seizure mechanisms. Previous studies (Racine, 1972b) Tanaka, 1972) have suggested, for instance, that the onset of GC's might be related to the onset of reactive propagation in various secondary structures. This is obviously not the case for any of the secondary structures studied in the present experiment, since directly eliciting AD's in them does not cause GC's. It might still be postulated, however, that the slower-kindling sites trigger GC's indirectly by kindling the faster sites and then driving GC's through them. The amygdala, of course, would be an obvious candidate for the role of "secondarily activated fast site". It is one of the quickest limbic sites to kindle and, as Tables $4 \& 5$ suggest, it can be activated by the slower sites. Goddard et al. (1969) have even suggested that kindling rate may be roughly related to neuroanatomical closeness to the amygdala. Unfortuantely, examination of the data does not provide much support for this hypothesis. Analysis of the relationship between the onset of secondary reactive discharge and the onset of GC's (Table 6) indicates that while reactive discharge has started in most secondary sites (including the amygdala) before GC onset, it has seldom occurred often enough to be suspected of "kindling" them. In most groups there are even a few subjects in which secondary site discharge started after GC onset. The only case in which a slow site clearly could have driven GC's through a faster site is that of the dorsal hippocampus driving the septal area. In this case, curiously enough, all the secondary septal sites had more than enough reactive AD's to kindle them, but apparently without beginning to trigger GC's on their own. This finding, which seems somewhat hard to understand, may relate to the proactive interference effects recently demonstrated by McIntyre and Goddard (1973). It certainly does not, however, support the notion that limbic structures cause GC's by propagating discharge through each other.

A further hypothesis related to propagation is Racine's suggestion that during primary kindling each propagated reactive discharge works like a directly elicited $\mathrm{AD}$ to prom-

TABLE 5

Numbers of $\mathrm{AD}^{\prime} \mathrm{s}$ Required

to Cause Reactive Propagation

\begin{tabular}{|c|c|c|c|c|c|c|}
\hline & & & AMYG & SEPT & $\mathrm{dHPC}$ & vHPC \\
\hline AMYG & $P$ & $\begin{array}{l}\overline{\mathrm{m}} \\
\mathbf{r}\end{array}$ & & $\begin{array}{c}6.8 \\
(4-9) \\
N=5\end{array}$ & $\begin{array}{l}10.0^{*} \\
(5-19) \\
N=8\end{array}$ & $\begin{array}{c}10.3^{*} \\
(2-22) \\
N=7\end{array}$ \\
\hline & $\mathrm{T}$ & $\begin{array}{l}\overline{\mathrm{m}} \\
\mathbf{r}\end{array}$ & & $\begin{array}{c}2.2 \\
(1-4) \\
N=5\end{array}$ & $\begin{array}{c}3.0 \\
(2-5) \\
N=4\end{array}$ & $\begin{array}{c}1.7 \\
(1-5) \\
N=6\end{array}$ \\
\hline SEPT & $\mathrm{P}$ & $\begin{array}{c}\overline{\mathrm{m}} \\
\mathrm{r}\end{array}$ & $\begin{array}{c}14.5 \\
(12-20) \\
N=5\end{array}$ & & $\begin{array}{c}8.4 \\
(1-28) \\
N=8\end{array}$ & $\begin{array}{c}7.2 \\
(1-24) \\
N=6\end{array}$ \\
\hline & $\mathrm{T}$ & $\begin{array}{l}\overline{\mathrm{m}} \\
\mathbf{r}\end{array}$ & $\begin{aligned} & 7.8 \\
(3 & -13) \\
N & =5\end{aligned}$ & & $\begin{array}{c}1.9 \\
(1-5) \\
N=7\end{array}$ & $\begin{array}{c}1.2 \\
(1-2) \\
N=6\end{array}$ \\
\hline $\mathrm{dHPC}$ & P & $\begin{array}{c}\overrightarrow{\mathrm{m}} \\
\mathrm{r}\end{array}$ & $\begin{array}{c}25.4 \\
(24-27) \\
N=5\end{array}$ & $\begin{array}{c}3.4 \\
(1-12) \\
N=7\end{array}$ & & \\
\hline & $\mathrm{T}$ & $\begin{array}{l}\overline{\mathrm{m}} \\
\mathrm{r}\end{array}$ & $\begin{array}{c}24.1 \\
(4-50) \\
N=8\end{array}$ & $\begin{array}{c}10.9 \\
(1-29) \\
N=8\end{array}$ & & \\
\hline vHPC & $\mathrm{P}$ & $\begin{array}{l}\overline{\mathrm{m}} \\
\mathrm{r}\end{array}$ & $\begin{aligned} & 6.2 \\
(1 & -17) \\
N & =6\end{aligned}$ & $\begin{array}{c}3.5 \\
(1-14) \\
N=6\end{array}$ & & \\
\hline & $\mathrm{T}$ & $\begin{array}{l}\overline{\mathrm{m}} \\
\mathrm{r}\end{array}$ & $\begin{array}{c}10.5 \\
(2-17) \\
N=6 * *\end{array}$ & $\begin{array}{c}4.5 \\
(1-9) \\
N=6\end{array}$ & & \\
\hline
\end{tabular}

* Includes one subject that never developed reactive discharge (scored as actual number of discharges plus one).

** Data lost for one subject. 
ote independent secondary seizure development and to reduce by one the number of transfer stimulations that will eventually be necessary to kindle the site. This hypothesis, though eminently reasonable in the light of Racine's discovery of active $A D$ as the causal factor in kindling (1972b), is not easy to test because of the problems in scoring reactive $\mathrm{AD}$. Column 6 of Table 1 indicates the average number of estimated reactive discharges which had occurred in each of the transfer sites before the start of transfer stimulation. These data, admittedly imprecise, do seem to support Racine's hypothesis. In groups where the average number of previous reactive discharges was equal to or greater than the number of primary discharges normally required for primary kindling (marked with a star), large amounts of transfer were seen and immediate transfer was common. In the other groups (no star), less transfer was seen (Mann-Whitney U Test; $p<0.002$, two-tailed), and the sum of the previous reactive discharges plus the number of directly-elicited AD's required to trigger the first GC often roughly approximated the normal primary kindling rate (Column 1). The amount of transfer observed, then, seemed to depend on the amount of reactive propagation which had occurred between sites. While these data can hardly be said to prove Racine's hypothesis, they are certainly consistent with it.

b) During Transfer Kindling: The present experiment provided data on only one particular type of transfer site propagation, propagation from transfer sites back to the original primary sites. Since the primaries had all been kindled, these data obviously do not offer an entirely safe basis on which to generalize. Still, they are of interest per se, and since Racine et al. (1972) have shown that kindled sites do not change their evoked potential responsiveness, they may well offer a generally valid picture.

As seen in the present study, transfer site propagation, like transfer site local AD's, tended to be mature or relatively mature from the
TABLE 6

Relation of the Onset of

Reactive Propagation to GC Onset*

Recording Site

\begin{tabular}{|c|c|c|c|c|c|}
\hline & & AMYG & SEPT & $\mathrm{dHPC}$ & vHPC \\
\hline AMYG & $\begin{array}{l}\text { II } \\
\text { r }\end{array}$ & & $\begin{array}{c}+4.0 \\
(+6 \text { to }+1) \\
N=5\end{array}$ & $\begin{array}{c}+0.9 * \star \\
(+8 \text { to }-10) \\
N=8\end{array}$ & $\begin{array}{c}-0.7 * * \\
(+4 \text { to }-10) \\
N=7\end{array}$ \\
\hline SEPT & $\begin{array}{c}\overline{\mathrm{m}} \\
\mathrm{r}\end{array}$ & $\begin{array}{c}+4.6 \\
(+8 \text { to } 0) \\
N=5\end{array}$ & & $\begin{array}{c}+4.0 \\
(+12 \text { to }-7) \\
N=8\end{array}$ & $\begin{array}{c}+13.7 \\
(+28 \text { to }-2) \\
N=6\end{array}$ \\
\hline dHPC & $\begin{array}{l}\overline{\mathrm{m}} \\
\mathrm{r}\end{array}$ & $\begin{array}{l}+3.8 \\
(+19 \text { to }-2) \\
N=5\end{array}$ & $\begin{array}{c}+42.0 \\
(+59 \text { to }+29) \\
N=7\end{array}$ & & \\
\hline vHPC & $\begin{array}{l}\overline{\mathrm{m}} \\
\mathrm{r}\end{array}$ & $\begin{array}{l}+11.2 \\
(+18 \text { to }+5) \\
N=6\end{array}$ & $\begin{array}{c}+19.0 \\
(+26 \text { to } 0) \\
N=6\end{array}$ & & \\
\hline
\end{tabular}

* Simultaneous onset is scored as " 0 ". When reactive discharge started before GC onset a " + " score is given. When reactive discharge started after GC onset a "-" score is given.

** Contains one subject which never developed reactive discharge (scored as " $-10 ")$. start. Immediate propagation of some sort was seen in all the secondary sites except for a few of the dorsal hippocampi (Table 4), and reactive propagation, when it was not immediately present, tended to develop much more rapidly than during primary kindling (Table 5). A noteworthy exception to this general pattern was seen in hippocampal S's where reactive propagation took as long or longer to develop as it had during primary kindling. This data seems to add to the other evidence that hippocampal output may be at least partly inhibitory, and also to suggest (since the hippocampal subjects did show significant transfer)
TABLE 7

Latencies (Sec) of the 1st and 10th GC's Elicited During Primary Kindling*

\begin{tabular}{|c|c|c|c|}
\hline Site & 1st GC & 10 th GC & $\overline{\mathrm{m}}_{\mathrm{R}}$ \\
\hline $\begin{array}{l}\text { AMYG } \overline{\frac{\mathrm{m}}{\mathrm{r}}} \\
\mathrm{N}=10^{\mathrm{r}}\end{array}$ & $\begin{array}{c}30.5 \\
(0.5-64.5)\end{array}$ & $\left(0.0^{4.9}-16.0\right)$ & 17.7 \\
\hline $\begin{array}{l}\text { SEPT } \overline{\mathrm{m}} \\
\mathrm{N}=10^{\mathrm{r}}\end{array}$ & $\begin{array}{c}43.2 \\
(4.0-86.5)\end{array}$ & $\begin{array}{c}12.4 \\
(0.0-37.5)\end{array}$ & 27.8 \\
\hline $\begin{array}{l}\mathrm{dHPC} \overline{\mathrm{m}} \\
\mathrm{N}=10^{\mathrm{r}}\end{array}$ & $\begin{array}{l}30.5 \\
(15.0-42.0)\end{array}$ & $\begin{array}{c}18.5 \\
(11.0-30.0)\end{array}$ & 24.5 \\
\hline $\begin{array}{l}\text { vHPC } \frac{\pi}{r} \\
\mathrm{~N}=10^{r}\end{array}$ & $\begin{array}{c}37.5 \\
(0.5-87.5)\end{array}$ & $\begin{array}{c}18.1 \\
(1.0-49.0)\end{array}$ & 27.8 \\
\hline$\overline{\mathrm{m}}_{\mathrm{C}}$ & 35.4 & 13.4 & \\
\hline
\end{tabular}

* Analysis of variance indicates overall significance, plus a columns effect significant at the $0.5 \%$ level. 
that limbic-limbic propagation is not the crucial factor involved.

Relative to the mechanism of transfer, it may be noted that not oniy were the transfer sites sometimes seen to trigger GC's without driving their primaries to active discharge, they were also occasionally seen to drive their primaries to active discharge before GC onset. This is consistent with Racine's finding that lesioning primary sites does not affect transfer (1972b), and seems to suggest that transfer sites do not trigger convulsions by activating their primaries. The fact that the primaries can actively discharge without triggering GC's is somewhat puzzling, but once again may indicate the action of interference effects.

\section{Development of Generalized}

\section{Convulsions}

a) During Primary Kindling: As described by previous investigators, (Goddard et al., 1969; Racine, 1972b), the development of convulsive behavior in limbic-kindled animals is a complex progression which starts well before GC onset with a series of partial seizures (eye blinks, mouth jerks, etc.), and which continues long afterwards, as GC's develop longer durations and shorter latencies. Tables 7 and 8 document the significant changes in GC latency and duration which were seen between the first and the 10th GC's in the present experiment. On the average, mature GC's began more than twice as quickly as early ones and lasted almost twice as long. Mature GC's also tended to be stronger as rated by Racine's seizure stages. In all the groups, S's were significantly more likely to have Stage 5 seizures during their last two seizure days than during their first two $\left(\mathrm{X}^{2}\right.$ for each group yields a $p<.05$ ).

Marked differences between the GC's triggered from different sites were not found. All of them belonged to the "subcortical" type described by previous experimenters (Goddard et al., 1969; Racine, 1972 b) and were roughly similar in latency and duration. Average duration was somewhat shorter for dorsal hippocampal subjects (Table 8 ) which may relate to the (nonsignificant) trend for their GC's to start later (Table 7).

Individual growth profiles plotted

TABLE 8

Durations (Sec) of the 1st and 10th GC's Elicited During Primary Kindling

\begin{tabular}{|c|c|c|c|}
\hline Site & 1st GC & 10 th GC & $\overline{\mathbf{m}}_{\mathrm{R}}$ \\
\hline $\begin{array}{l}\text { AMYG } \overline{\bar{m}} \\
\mathrm{~N}=10^{\mathrm{r}}\end{array}$ & $\begin{array}{c}39.5 \\
(5.0-90.5)\end{array}$ & $\begin{array}{l}49.7 \\
(25.0-72.5)\end{array}$ & 44.6 \\
\hline $\begin{array}{l}\text { SEPT } \frac{\bar{m}}{\mathrm{r}} \\
\mathrm{N}=10^{-1}\end{array}$ & $\begin{array}{c}23.3 \\
(3.0-67.0)\end{array}$ & $\begin{array}{l}41.5 \\
(35.0-58.0)\end{array}$ & 32.4 \\
\hline $\begin{array}{l}\mathrm{dHPC} \overline{\mathrm{m}} \\
\mathrm{N}=10^{\mathrm{r}}\end{array}$ & $\begin{array}{c}17.8 \\
(9.0-33.0)\end{array}$ & $\begin{array}{c}34.0 \\
(17.5-49.0)\end{array}$ & 26.0 \\
\hline $\begin{array}{l}\operatorname{vHPC} \overline{\mathrm{m}} \\
\mathrm{N}=10^{\mathrm{r}}\end{array}$ & $\begin{array}{c}29.3 \\
(6.5-91.0)\end{array}$ & $\begin{array}{l}51.8 \\
(24.5-80.5)\end{array}$ & 40.6 \\
\hline$\overline{\mathrm{m}}_{\mathrm{C}}$ & 27.5 & 44.3 & \\
\hline
\end{tabular}

* Analysis of variance indicates overall significance, plus significant rows $(2.5 \%$ leve 1$)$ and columns $(0.5 \%$ leve1) effects. Individual comparisons (Scheffé Method) for the row means reveal a significant difference only between the amygdaloid and dorsal hippocampal groups ( $5 \%$ leve 1 ).

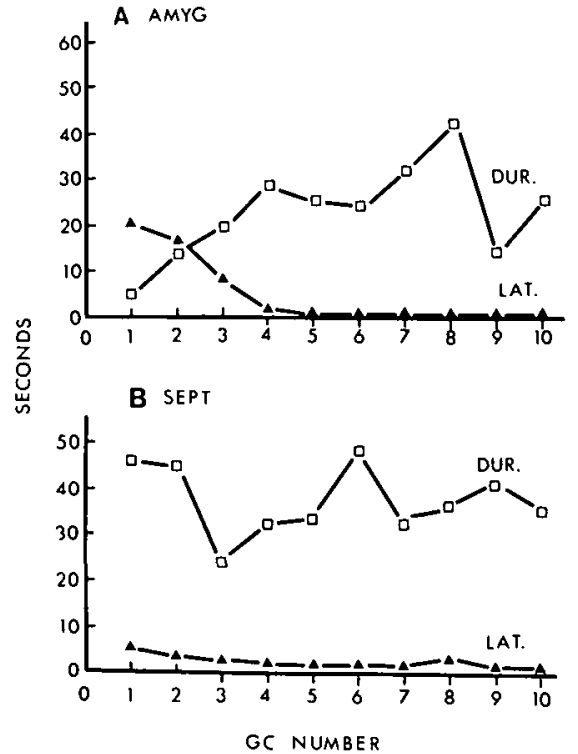

Figure 5-Profiles plotted for GC latency (lat.) and duration (dur.) during primary kindling. A: The gradual development seen in most S's. B: The early maturity seen in a few S's.

for GC's did not show the clear-cut steps seen in AD growth. Bascially, the GC growth pattern seemed to be one of gradual increase followed at maturity by random variation (Figure 5-A). In individual records, such growth could be seen to go on for as long as 10 convulsions. GC growth also differed from $A D$ growth in that mature, full-length GC's sometimes appeared right from the start, often with short latencies and Stage 5 development (Figure 5B).

b) During Transfer Kindling: One might not have expected to find in transfer GC's the early maturity that had previously been seen in local and propagated AD's. Judging by the electrographic phenomena, most of the transfer S's appeared to be in the later stages of pre-convulsive $A D$ growth at the start of transfer stimulation. These S's might have been expected to produce "early" GC's when GC onset occurred.

Transfer GC latencies appeared to conform pretty well to this analysis. Though they were significantly shorter at onset than initial primary latencies (Table 9), the difference was not a very large one (see Table 7 for "mature" latencies) and was contributed almost entirely by the amygdaloid and septal groups, 
groups in which a good number of S's displayed immediate transfer. Immediate transfer S's may well have passed the point of GC onset in their development and gone on into the early convulsive period.

In duration and strength, on the other hand, transfer GC's tended to be mature from the very start. They were convincingly longer (Table 10) and stronger ( $\mathrm{X}^{2}$ significant at the $5 \%$ level for all groups except the ventral hippocampals), than primary GC's had been at onset, and generally resembled the convulsions seen toward the very end of primary stimulation. This was true even in groups like the dorsal hippocampals in which there was no immediate transfer, and where most subjects had to go through a fairly long period of $A D$ growth before the first GC occurred.

This difference between transfer latencies on one hand and strength and durations on the other, suggests that two different mechanisms may be involved: 1) a convulsive mechanism (discharge in some "downstream" structure?) which is fully developed by primary kindling; and 2) a triggering mechanism (changes in pathways between the triggering site and the convulsive mechanism?) which is related to latency and AD growth and which may be only partly developed during primary kindling.

Retesting of the Primary Site: Interference: Goddard et al . (1969), using a fairly low level of standard stimulation, reported that after a transfer site had been kindled, stimulation of the primary site would not elicit convulsions until a few more stimulations had been given to "reestablish the response". Racine (Personal Communication), who uses higher currents for standard stimulation, has failed to find such post-transfer interference, and has suggested that Goddard may simply be failing to re-elicit primary site AD's. McIntyre and Goddard (1973), however, have recently shown that primary site AD can occur during the interference period, and it has not been quite clear why the two groups differ in their results.
TABLE 9

Onset Latencies (Sec) of Primary and Transfer GC's*

\begin{tabular}{|c|c|c|c|c|}
\hline \multicolumn{2}{|c|}{ Site } & \multirow{2}{*}{$\begin{array}{c}\text { Primary } \\
\begin{array}{c}30.5 \\
(0.5-64.5) \\
N=10\end{array}\end{array}$} & \multirow{2}{*}{$\begin{array}{c}\text { Transfer } \\
\begin{array}{c}23.0 \\
(0.5-47.0) \\
N=16\end{array}\end{array}$} & \multirow{2}{*}{$\frac{\overline{\mathrm{m}}_{\mathrm{R}}}{26.8}$} \\
\hline AMYG & $\begin{array}{l}\overline{\mathrm{m}} \\
\mathrm{r}\end{array}$ & & & \\
\hline SEPT & $\begin{array}{l}\overline{\mathrm{m}} \\
\mathrm{r}\end{array}$ & $\begin{array}{c}43.2 \\
(4.0-86.5) \\
N=10\end{array}$ & $\begin{array}{c}19.0 \\
(2.5-45.0) \\
N=18\end{array}$ & 31.1 \\
\hline dHPC & $\begin{array}{l}\overline{\mathrm{m}} \\
\mathrm{r}\end{array}$ & $\begin{array}{c}30.5 \\
(15.0-42.0) \\
N=10\end{array}$ & $\begin{array}{c}30.0 \\
(14.0-50.5) \\
N=16\end{array}$ & 30.2 \\
\hline vHPC & $\begin{array}{c}\overline{\mathrm{m}} \\
\mathrm{r}\end{array}$ & $\begin{array}{c}37.5 \\
(0.5-87.5) \\
N=10\end{array}$ & $\begin{array}{c}37.5 \\
(3.0-76.0) \\
N=12\end{array}$ & 37.5 \\
\hline & $\overline{\mathrm{m}}_{\mathrm{C}}$ & 35.4 & 27.4 & \\
\hline
\end{tabular}

* Analysis of variance (unweighted means solution) indicates overall significance, plus a columns effect significant at the $5 \%$ level.

TABLE 10

Onset Durations (Sec) of Primary and Transfer GC's*

\begin{tabular}{|c|c|c|c|c|}
\hline \multicolumn{2}{|c|}{ Site } & \multirow{2}{*}{$\begin{array}{c}\text { Primary (Sec) } \\
\begin{array}{c}39.5 \\
(5.0-90.5) \\
N=10\end{array}\end{array}$} & \multirow{2}{*}{$\begin{array}{l}\text { Transfer (Sec) } \\
\begin{array}{c}45.6 \\
(1.0-81.5) \\
N=16\end{array}\end{array}$} & \multirow{2}{*}{$\frac{\overline{\mathrm{m}}_{\mathrm{R}}}{42.5}$} \\
\hline AMYG & $\begin{array}{l}\overline{\mathrm{m}} \\
\mathrm{r}\end{array}$ & & & \\
\hline SEPT & $\begin{array}{l}\overline{\mathrm{m}} \\
\mathrm{r}\end{array}$ & $\begin{array}{c}23.4 \\
(3.0-67.0) \\
N=10\end{array}$ & $\begin{array}{c}47.3 \\
(6.0-111.5) \\
N=18\end{array}$ & 35.3 \\
\hline $\mathrm{dHPC}$ & $\begin{array}{l}\overline{\mathrm{m}} \\
\mathrm{r}\end{array}$ & $\begin{array}{c}17.9 \\
(9.0-33.0) \\
N=10\end{array}$ & $\begin{array}{c}42.9 \\
(5.0-81.5) \\
N=16\end{array}$ & 30.4 \\
\hline vHPC & $\begin{array}{l}\overline{\mathrm{m}} \\
\mathrm{r}\end{array}$ & $\begin{array}{c}29.4 \\
(6.5-91.0) \\
N=10\end{array}$ & $\begin{array}{c}30.5 \\
(5.5-67.0) \\
N=12\end{array}$ & 29.9 \\
\hline & $\overline{\mathrm{m}}_{\mathrm{C}}$ & 27.5 & 41.6 & \\
\hline
\end{tabular}

* Analysis of variance (unweighted means solution) indicates overall significance, plus a columns effect significant at the $0.5 \%$ level. 
Data from the present study (Table 11) indicate that post-transfer interference can be found even when relatively high levels of current are used and AD's are regularly evoked. Significant amounts were found, however, only when the amygdala was the site used for transfer kindling. Other transfer sites produced only insignificant trends toward interference. The amygdala itself never showed the slightest sign of interference. There was considerable variation in the AD's seen during the interference period, but some at least were as long and well propagated as AD's which had previous triggered GC's from the site.

The results of the present experiment confirm Goddard et al's previous reports of interference. Racine probably failed to find it only because he tended to use the amygdala as a primary site in his transfer experiments.

\section{DISCUSSION}

Data from the present study, taken together with data from previous studies of contralateral kindling, show transfer to be a phenomenon widespread throughout the limbic system. It does not seem to be limited to particular structures, systems or pathways. To the extent that a pattern can be detected, transfer seems to follow the course of AD propagation. If this is the case, future studies may well show transfer throughout the whole brain, not just in limbic sites.

The present study provides some support for both of the hypothetical mechanisms of transfer which have been proposed. The mature patterns of discharge and propagation found from the start of transfer kindling are consistent with the view that reactive propagation partially kindles transfer sites during the period of primary stimulation. The finding of a rough correspondence between amount of transfer and the amount of previous reactive propagation also supports this view. On the other hand, the immediate maturity of transfer convulsions fits better with the notion of tying in to pre-formed circuits. Of course, the two mechanisms are not mutually exclu- sive, and it seems quite possible that they function together. The only puzzling question is why tying in does not work at higher levels to cause an even faster onset of transfer GC's. Here we can only note the observation that transfer sites sometimes drive their primaries without causing convulsions, and refer once more to the interference effects demonstrated by McIntyre and Goddard.

The data on transfer may profitably be set within the larger framework of what we know, or can guess, about primary seizure mechanisms. Clinically oriented theorists (Penfield and Jasper, 1954; Gastaut and Fischer-Williams, 1959) see the development of focal attacks as a progression of active discharge through the brain, one structure setting off the next until a GC occurs. This conception is entirely consistent with the spread of propagation we see in kindled animals. We may even speculate that the "steps" seen in $\mathrm{AD}$ growth reflect the onset of propagation in downstream structures which then feed-back facilitation to primary sites as well as going on to recruit further downstream structures.
The similarity of the AD steps seen in different S's further suggests that there may be two or three important downstream structures common to all of limbic seizure development. Centrencephalic theory would indicate that these crucial structures ought to be in the brainstem. This idea also seems consistent with the present data on kindling: early studies by Delgado and Sevillano (1961) on a kindling-like preparation showed that removal of the motor cortex does not stop GC's; recent kindling studies on split-brain preparations (Wada and Sato, 1973; McIntyre, 1975) indicate that an interruption of contralateral propagation does not block their development; and data from the present experiment suggest that ipsilateral limbic-limbic links are not crucial. Limbic-brainstem links seem a good possibility. Perhaps the role of the hypothalamus, an important target for projections from many limbic sites, ought to be investigated.

Though limbic-limbic links would not seem to be crucial for primary seizure development, they may well be basic to the development of transfer. Presumably it is through such "same-level" connections that reac-

TABLE 11

Primary Site Stimulations Failing to Cause GC's in Well Kindled S's

\begin{tabular}{|c|c|c|c|c|c|c|c|}
\hline \multirow[t]{2}{*}{ Primary Site } & \multirow[t]{2}{*}{ Transfer Site } & \multicolumn{2}{|c|}{$\begin{array}{c}1 \\
\text { Pre-transfer } \\
\text { (Spontaneous) }\end{array}$} & \multicolumn{2}{|c|}{$\begin{array}{l}\quad 2 \\
\text { Post-transfer } \\
\text { (Interference) }\end{array}$} & \multirow[t]{2}{*}{$2^{p^{* \star *}}$ vs. 1} & \multirow{2}{*}{$\begin{array}{l}\% A D^{\prime} s \\
\text { During } \\
\text { Interference }\end{array}$} \\
\hline & & & & $\overline{\mathrm{m}}$ & & & \\
\hline \multirow[t]{3}{*}{ AMYG } & SEPT $(N=5)$ & 0.0 & $(---)$ & 0.0 & $(---)$ & n.s. & - \\
\hline & $\mathrm{dHPC}(\mathrm{N}=7)$ & 0.0 & $(---)$ & 0.0 & $(---)$ & n.s. & - \\
\hline & vHPC $(N=4)$ & 0.0 & $(---)$ & 0.0 & $(---)$ & n.s. & - \\
\hline \multirow[t]{3}{*}{ SEPT } & AMYG $(N=6)$ & 0.2 & $(0-1)$ & 1.5 & $(0-3)$ & $\mathrm{p}<0.05$ & 100.0 \\
\hline & $\mathrm{dHPC} \quad(\mathrm{N}=7)$ & 0.0 & $(---)$ & 0.9 & $(0-4)$ & n.s. & 83.3 \\
\hline & $\operatorname{vHPC} \quad(\mathrm{N}=6)$ & 0.0 & $(---)$ & 0.3 & $(0-2)$ & n.s. & 100.0 \\
\hline \multirow[t]{2}{*}{ dHPC } & AMYG $(N=5)^{\circ}$ & 0.4 & $(0-1)$ & 1.6 & $(0-5)$ & n.s. & so.0 \\
\hline & SEPT $\quad(N=6)$ & 0.0 & $(---)$ & 1.0 & $(0-3)$ & n.s. & 0.0 \\
\hline \multirow[t]{2}{*}{ vHPC } & AMYG $(N=6)$ & 0.2 & $(0-1)$ & 2.0 & $(1-3)$ & $\mathrm{p}<0.02$ & 100.0 \\
\hline & SEPT $(N=5)$ & 0.4 & $(0-2)$ & 0.4 & $(0-1)$ & n.s. & 50.0 \\
\hline
\end{tabular}

* Measured between the ninth and tenth pre-transfer GC's.

** Measured before the recurrence of post-transfer GC's.

*** One-tailed probabilities calculated by Wilcoxon's Matched-pairs signed-ranks test (Ferguson, 1971). 
tive discharge propagates into transfer sites causing them to start forming their own limbic-brainstem chains of potentiated pathways.

Regarding the clinical significance of transfer, the transfer data seem to indicate that repeated local discharges can cause neural reorganization throughout very widespread areas of the brain. These may involve hyper-potentiation of pathways, which may, as Adamec's (1975) recent work seems to show, have considerable functional significance. The fact that epileptic patients function normallly between attacks indicates that the regulatory mechanisms of the brain sooner or later manage to compensate for this reorganization. Still, clinicians may want to consider the advisibility of preventing as much of it as possible through vigorous treatment of the earliest signs of epilepsy.

\section{DISCUSSION}

Dr. Goddard: I would like to ask a point for information. I am particularly interested in this finding that during transfer kindling, you occasionally see an example where during secondary kindling, prior to the onset of a generalized behavioral convulsion, you see a fully mature afterdischarge in the primary site driven from the transfer site or reactive discharge in the primary site set off by the secondary transfer site. The example that you showed was the hippocampus. I was wondering if you have ever seen this in the primary amygdala? Dr. Burnham: I believe that I did but 1 will check my records and let you know later. Dr. Goddard: The reason that I asked is I would find it surprising because you couldn't say that this is an effect of the retroactive interference for example, if there were interference in the amygdala. The only occasion that I have seen it is when the other amygdala was stimulated, which you weren't doing, so there is not much interference at the amygdala level. Furthermore, in the McIntyre \& Goddard series, we didn't find any interference prior to the first generalized behavioral convulsion. It only followed after the behavioral convulsions were triggered from the secondary amygdala and then you got the interference so that you were in a situation where there is no, or very little, interference in measurable quantities and it is very surprising if the primary amygdala was going off at full discharge together with the secondary site if it doesn't emerge in a convulsion. Dr. Burnham: You're right, the amygdala seems super resistant to interference anywhere. I would like to look at the records and talk to you about that. I couldn't say a definite yes or no at this time. Dr. Morrell: Don't you see spontaneous spiking in the rat? Dr. Burnham: This is a marvelous point. You don't see the sort of spontaneous spiking you have reported from the frog. What you do see is, if you read Dave Walters' study, if you kindle an animal, particularly in the amygdala, you will see what we have called interictal spiking after a well developed seizure and it will last for hours and days. I haven't seen these sort of independent spikes in secondary structures ever in any of my animals and I don't know if anybody else has. Dr. Morrell: Wada and I have both found spikes in the amygdala in cats, and Racine has found it in rats. Could it be that in the data on afterdischarge duration and so on that those spikes relate not only to that but also to the density of interictal spiking? Dr. Burnham: Not in my animals. I judge from what Dr. Pinel has done that if you kindle the primary site long enough you can get your spontaneous focus and that probably you could get spontaneous focus in the site of propagation too. Dr. Wada: In our experience, there are certain species differences which should be mentioned. Firstly, we have not observed, in rhesus monkeys or in baboons, the propagation of afterdischarge into the contralateral amygdala until the animals have reached the final stage of seizure development. Secondly, in both cats and primates, we have not been able to observe post-transfer interference; that is. if you do transfer and then come back, you can get a kindled convulsion on the first stimulation of the primary site. Thirdly, we have observed interictal discharge taking place 24 hours following each brain stimulation, that is, immediately prior to the next stimulation in cats, rhesus monkeys and baboons, and we know now that at least in cats and baboons they persist at least one year following the termination of the brain stimulation. Dr. McIntyre: Did you have electrodes bilaterally in the amygdala? Dr. Wada: Yes, all our animals had electrodes placed bilaterally in the amygdala, hippocampus, basal ganglia and brainstem structures so that I think we have a fair idea as to topographic pattern and evolution of afterdischarge and interictal discharge.

\section{ACKNOWLEDGEMENTS}

This work was supported by National Research Council Grant PA 66 awarded to Dr. Peter M. Milner. The author would like to thank Dr. Milner, and also Doctors Ronald Racine and Michael Corballis for valuable advice and discussion.

\section{REFERENCES}

ADAMEC, R. (1975). Behavioral and epileptic determinants of predatory attack behavior in the cat. Can. Journal Neurol. Sciences. This issue.

BURNHAM, W. M. (1971). Epileptogenic modification of the rat forebrain by direct and trans-synaptic stimulation. Unpublished Doctoral Dissertation, McGill University, Quebec, Canada.

DELGADO, J. M. R. and SEVILLANO, M. (1961). Evolution of repeated hippocampal seizures in the cat. Electroenceph. Clin. Neurophysiol., 13, 722-733.

ELUL, R. (1964). Regional differences in the hippocampus of the cat. II. Projections of the dorsal and ventral hippocampus. Electroenceph. Clin. Neurophysiol., 16, 489-502.
FERGUSON, G. (1971). Statistical Analysis in Psychology and Education (3rd Edition), McGraw-Hill Book Company Inc., New York.

GASTAUT, $H$. and FISCHER-WILLIAMS, M. (1959). Physiopathology of epileptic seizures. In Handbook of Physiology, Section I. Neurophysiology. Eds. Field, J., Magoun, H., and Hall, V., 329-363.

GODDARD, G.V., McINTYRE, D. and LEECH, C. (1969). A permanent change in brain function resulting from daily electrical stimulation. Exp. Neurol., 25, 295-330.

McINTYRE, D. C. (1975). Split brain rat: Transfer and interference of kindled amygdaloid convulsions. Can. Journal Neurol. Sciences. This issue.

MCINTYRE, D. C. and GODDARD, G. V. (1973). Transfer, interference and spontaneous recovery of convulsions kindled from the rat amygdala. Electroenceph. Clin. Neurophysiol., 35, 533-543.

MORRELL, F. (1973). Goddard's kindling phenomenon: A new model of the "mirror focus". In Chemical Modulation of Brain Function. Ed. H. C. Sabelli, Raven Press, New York, 207-223.

PELLEGRINO, L. and CUSHMAN, A. (1967). A stereotaxic atlas of the rat brain. New York: Appleton-Century-Crofts.

PENFIELD, W. and JASPER, H. H. (1954). Epilepsy and the functional anatomy of the human brain. Boston: Little, Brown and Company.

RACINE, R. J. (1972a). Modification of seizure activity by electrical stimulation: I. Afterdischarge threshold. Electroenceph. Clin. Neurophysiol., 32, 269-279.

RACINE, R. J. (1972b). Modification of seizure activity by electrical stimulation: II. Motor seizure, Electroenceph. Clin. Neurophysiol., 32, 281-294.

RACINE, R. J., BURNHAM, W. M. and GARTNER, J. G. (1973). First trial motor seizures triggered by amygdaloid stimulation in the rat. Electroenceph. Clin. Neurophysiol., 35, 487-494.

RACINE, R. J., BURNHAM, W. M., GARTNER, J. G. and LEVITAN, D. (1973). Rates of motor seizure development in rats subjected to electrical brain stimulation: Strain and interstimulation interval effects. Electroenceph. Clin. Neurophysiol., 35, 553-556.

RACINE, R. J., GARTNER, J. G. and BURNHAM, W. M. (1972). Epileptiform activity and neural plasticity in limbic structures. Brain Research, 47, 262-268.

TANAKA, A. (1972). Progressive changes of behavioral and electroencephalographic responses to daily amygdaloid stimulations in rabbits. Fukuoka Acta Medica, 63, 152-164.

WADA, J. A. and SATO, M. Generalized convulsive seizure state induced by daily electrical stimulation of the amygdala in split-brain cats. Delivered at Annual Convention of Am. EEG Assn., June 15. 1973 (Boston, Mass.).

WINER, B. (1962). Statistical principles in experimental design. McGraw-Hill Book Company Inc., New York. 